\title{
Uji Daya Hambat Ekstrak Metanol Beberapa Jenis Porifera Terhadap Bakteri Escherichia coli dan Staphylococcus aureus
}

\author{
Megawati S. Saroinsonga*, Febby E.F Kandoua, Adelfia Papua, \\ Marina F.0. Singkoha
}

aJurusan Biologi, FMIPA, Unsrat, Manado

\begin{tabular}{l}
\hline K A T A K U N C I \\
\hline Porifera \\
Haliclona sp \\
Agelas sp \\
Spheciospongia sp \\
Antibakteri
\end{tabular}

\begin{abstract}
A B S T R A K
Penelitian ini bertujuan untuk menguji daya hambat dari ekstrak metanol beberapa jenis porifera terhadap pertumbuhan bakteri $E$. coli dan S. aureus. Pengujian aktivitas antibakteri menggunakan metode KirbyBauer, yaitu dilakukan dengan mengukur zona hambat di sekeliling cakram kertas. Ekstrak Haliclona sp dapat menghambat pertumbuhan S. aureus pada konsentrasi ekstrak 30\%, 60\% dan 90\% dengan hasil pengukuran diameter zona hambat $13.50 \mathrm{~mm}, 20.67 \mathrm{~mm}$ dan $27.33 \mathrm{~mm}$; serta menghambat pertumbuhan $E$. coli dengan diameter zona hambat $10.08 \mathrm{~mm}, 12.83 \mathrm{~mm}$ dan $14.17 \mathrm{~mm}$. Daya hambat ekstrak Agelas sp terhadap S. aureus menunjukkan diameter zona hambat $8.33 \mathrm{~mm}$ dan hanya menunjukkan pada konsentrasi ekstrak 90\%, sementara daya hambat ekstrak Agelas sp pada konsentrasi 30\%, 60\% dan 90\% terhadap E. coli menunjukkan diameter zona hambat sebesar $7.67 \mathrm{~mm}, 10.17 \mathrm{~mm}$ dan $14.17 \mathrm{~mm}$. Daya hambat Spheciospongia sp terhadap S. aureus dan E. coli hanya terlihat pada konsentrasi ekstrak sebesar $90 \%$ dengan diameter zona hambat adalah $8.42 \mathrm{~mm}$ dan $8.75 \mathrm{~mm}$. Berdasarkan hasil yang diperoleh, dapat disimpulkan bahwa ekstrak Haliclona sp memiliki potensi aktivitas antibakteri yang dapat digunakan sebagai bahan dasar pembuatan obat antibiotik.
\end{abstract}

\begin{tabular}{l}
\hline K E Y W O R D S \\
\hline Sponge \\
Haliclona sp \\
Agelas sp \\
Spheciospongia sp \\
Antibacteria
\end{tabular}

A B S T R A C T

This research aimed to test the inhibition capabilities of methanol extract from several kinds of Porifera on Escherichia coli and Staphylococcus aureus growth. The antibacterial activity test using the Kirby-Bauer method, which delivered by measuring the inhibition zone around paper disc. The extract of Haliclona sp can inhibit the S. aureus growth at 30\%, 60\% and $90 \%$ of extracts concentration with the measurement of inhibition zone diameters are $13.50 \mathrm{~mm}, 20.67 \mathrm{~mm}$ and $27.33 \mathrm{~mm}$; also inhibit the $E$. coli growth with inhibition zone diameters are $10.08 \mathrm{~mm}, 12.83 \mathrm{~mm}$ and $14.17 \mathrm{~mm}$. The inhibition capability of Agelas sp extract on $\mathrm{S}$. aureus shows that the inhibition zone diameters is $8.83 \mathrm{~mm}$ and only appear at $90 \%$ of extracts concentration, meanwhile the inhibition capability of Agelas sp extract at concentration 30\%, $60 \%$ and $90 \%$ on $E$. coli shows diameters of inhibition zone are $7.67 \mathrm{~mm}$, $10.17 \mathrm{~mm}$ and $14.17 \mathrm{~mm}$. The inhibition capability of Spheciospongia sp on S. aureus and $E$. coli only occurred at $90 \%$ of extracts concentration with inhibition zone diameters $8.42 \mathrm{~mm}$ and $8.75 \mathrm{~mm}$. Based on the results, it can be assumed that extracts of Haliclona sp has a potential antibacterial activity that can be used as a basic ingredients for antibiotic medicine. 


\section{Pendahuluan}

Penyakit infeksi yang disebabkan oleh mikroba merupakan masalah kesehatan yang harus ditangani. Banyak cara yang dilakukan untuk pengobatan berbagai jenis penyakit infeksi yaitu dengan cara pemberian obat antibiotik. Tingginya kasus infeksi serta penggunaan obat antibiotik yang tidak tepat atau terus menerus akan menyebabkan resisten mikroba terhadap antibiotik. Pengobatan mengenai penyakit-penyakit yang semakin hari terus meningkat menuntut peranan dari berbagai bidang untuk menemukan beragam jenis obat-obatan baru, khususnya pada biota laut (Astuti et al., 2003).

Porifera merupakan hewan multiseluler atau metazoa yang fungsi organ dan jaringannya masih sangat sederhana (Amir dan Budiyanto, 1996). Porifera mempunyai potensi bioaktif yang belum banyak dimanfaatkan dan menghasilkan senyawa bioaktif yang sangat besar di antara invertebrata laut lainnya (Kobayashi dan Rachmaniar, 1999 ; Proksch, 1999). Sampai saat ini banyak penelitian yang melakukan uji senyawa-senyawa pada biota laut yang mempunyai manfaat terhadap suatu penyakit. Porifera termasuk biota laut yang menghasilkan senyawa-senyawa metabolit sekunder yang memiliki peranan yang sangat potensial dalam bidang farmasi yang dijadikan sebagai obat (Rachmaniar, 2007). Senyawa-senyawa yang telah berhasil diisolasi dari beberapa jenis porifera di antaranya adalah alkaloid, terpenoid, acetogenin, senyawa nitrogen, halida siklik, peptide siklik dan lain-lain (Murniasih, 2003). Beberapa penelitian menunjukkan senyawa metabolit yang berhasil diisolasi dari jenis-jenis porifera yang memiliki aktifitas antikanker (Rachmaniar, 2003), antitumor (Nursid et al., 2006), antibakteri (Astuti et al., 2003), antijamur (Asaf, 2009) dan antivirus (Karyawati, 2010).

Senyawa bioaktif yang dihasilkan porifera merupakan salah satu proses adaptasi untuk mekanisme pertahanan diri (Murniasih, 2005). Senyawa bioaktif tersebut merupakan senyawa kimia yang disebut senyawa metabolit sekunder yang digunakan untuk menghindari diri dari serangan predator dan media kompetisi dengan spesies lain (Amir dan Budiyanto, 1996 ; Rachmaniar, 2007). Senyawa yang dihasilkan porifera merupakan respon terhadap kompetisi lingkungannya. Produk senyawa yang dihasilkan porifera merupakan hasil dari simbiotik antara beberapa organisme seperti alga, bakteri dan lainlain (Suparno, 2005). Lingkungan dari porifera sangat mempengaruhi proses pertumbuhan porifera karena dilihat dari sifat makan dari hewan ini yaitu menyaring makanan (filter feeder) (Amir dan Budiyanto, 1996).

Tiap jenis porifera menghasilkan senyawa metabolit yang berbeda. Senyawa metabolit sekunder mempunyai manfaat yang berbeda tergantung jenis senyawanya yaitu sebagai antikanker, antibakteri, antijamur dan lain-lain. Berdasarkan hal tersebut maka perlu dilakukan penelitian untuk mengetahui porifera yang mempunyai kemampuan sebagai antibakteri.

\section{Metode \\ 2.1. Waktu dan Tempat Penelitian}

Penelitian ini berlangsung selama dari bulan April-Juni 2014. Pengambilan sampel dilakukan di perairan Kepulauan Bunaken Manado dan uji laboratorium di Laboratorium Mikrobiologi FMIPA Universitas Sam Ratulangi.

\subsection{Material}

Alat-alat yang digunakan dalam penelitian ini adalah timbangan analitik, aluminium foil, sendok, gelas erlenmeyer $500 \mathrm{ml}$, gelas ukur $100 \mathrm{ml}$ dan $500 \mathrm{ml}$, pelat pemanas, batang pengaduk bermagnet, tabung reaksi, cawan petri, gelas piala $100 \mathrm{ml}$, autoklaf, kompor, kawat ose, lampu bunsen, kapas, korek api, rak tabung, mortar dan pestel, mikro pipet, tabung Eppendorf, laminar flow, inkubator, evaporator, pinset, kertas saring, kertas label, kertas cakram $5 \mathrm{~mm}$, lemari pendingin, penggaris, jangka sorong, sarung tangan dan kamera.

Bahan-bahan yang digunakan yaitu ekstrak porifera, biakan murni bakteri Escherichia coli dan Staphylococcus aureus, medium Nutrient Broth (NB), medium Nutrient Agar (NA) dan larutan metanol lisol (antiseptik).

\subsection{Pembiakan Bakteri}

Biakan bakteri Escherichia coli dan Staphylococcus aureus diinokulasi secara aseptik ke dalam tabung reaksi yang sudah berisi $5 \mathrm{ml}$ medium NB. medium tersebut diinkubasi selama 24 jam pada suhu $37^{\circ} \mathrm{C}$, kemudian diinokulasi lagi dari medium NB ke medium NA miring lalu diinkubasikan selama 24 jam lalu disimpan sebagai stok dari kedua bakteri tersebut.

\subsection{Pembuatan Ekstrak Porifera}

Sampel porifera yang berasal dari perairan Manado (Kepulauan Bunaken) diidentifikasi, kemudian dibersihkan dan dicuci dengan air laut lalu dimasukkan dalam wadah dan diawetkan di dalam cool box yang berisi es. Setelah sampai di laboratorium masing-masing sampel porifera dikeluarkan dari cool box. Setiap sampel porifera dipotong-potong kecil sebanyak 200 g dan dimasukkan dalam wadah maserasi, kemudian ditambahkan metanol sebanyak 100 ml. Setelah 24 jam pelarut diganti dengan metanol yang baru. Ini dilakukan sebanyak 3 kali dengan jumlah pelarut yang sama. Ekstrak metanol yang diperoleh dikumpulkan dan diuapkan dengan menggunakan evaporator. Ekstrak kental yang diperoleh dikeringanginkan sampai mendapatkan ekstrak kering porifera.

Ekstrak metanol yang diperoleh diberi perlakuan dengan konsentrasi yang berbeda-beda 
yaitu 30\%, 60\% dan 90\%. Selanjutnya digunakan sebagai sampel uji aktivitas antimikroba.

\subsection{Pengujian Daya Hambat Ekstrak Porifera Terhadap Aktivitas Antibakteri}

Pengujian efektivitas bakteri dilakukan dengan metode Kirby-Bauer atau Paper disk, yaitu dengan mengamati dan mengukur zona hambat ekstrak porifera. Inokulum dari masing-masing bakteri Escherichia coli dan Staphylococcus aureus diambil secara aseptik sebanyak $1 \mathrm{ml}$ dari medium NB dan dituangkan ke cawan petri yang sudah berisikan medium NA. Setelah itu kertas cakram yang berukuran kira-kira 0,5 $\mathrm{mm}$ dicelupkan ke dalam ekstrak porifera dengan konsentrasi yang berbeda yaitu 30\%, 60\% dan 90\%. Setelah itu dengan menggunakan pinset, kertas cakram diletakkan di atas masing-masing medium NA yang mengandung masing-masing bakteri $S$. aureus dan $E$. coli dan diinkubasikan pada temperatur $37^{\circ} \mathrm{C}$ selama $1 \times 24$ jam. Setelah itu semua media diinkubasi selama 24 jam pada temperatur $37^{\circ} \mathrm{C}$ lalu diamati dan diukur diameter zona hambatannya sampai hari ketiga.

\subsection{Analisis Data}

Diameter zona hambat yang diperoleh merupakan hasil rata-rata ekstrak spesies dari setiap kosentrasi tiga kali ulangan yang disajikan dalam tabel.

\section{Hasil dan Pembahasan}

Hasil uji rata-rata ekstrak porifera menunjukkan ekstrak Spheciospongia sp pada konsentrasi 30\% dan $60 \%$ tidak menunjukkan adanya diameter zona hambat yang terbentuk di sekitar cakram kedua bakteri (Tabel 1). Hal ini menunjukkan pada konsentrasi rendah ekstrak Spheciospongia $\mathrm{sp}$ belum mampu merusak dinding sel bakteri $S$. aureus dan E. coli. Menurut Rachmaniar (1997) ekstrak-ekstrak yang tidak menunjukkan adanya aktivitas senyawa bioaktif bukan berarti sampel tersebut tidak aktif, tetapi kemungkinan dipengaruhi oleh konsentrasi sampel uji yang digunakan. Ekstrak Spheciospongia sp pada konsentrasi 90\% sudah memperlihatkan adanya aktivitas antibakteri atau zona hambat di sekitar cakram. Rata-rata diameter zona hambat yang terbentuk yaitu $8.42 \mathrm{~mm}$ untuk bakteri S. aureus dan $8.75 \mathrm{~mm}$ untuk bakteri $E$. coli (Tabel 1).

Tabel 1. Diameter zona hambat ekstrak Spheciospongia sp terhadap bakteri Staphylococcus aureus dan Escherichia coli

\begin{tabular}{ccc}
\hline \multirow{2}{*}{ Konsentrasi } & \multicolumn{2}{c}{$\begin{array}{c}\text { Diameter Zona Hambat Ekstrak } \\
\text { Spheciospongia sp }(\mathrm{mm})\end{array}$} \\
\cline { 2 - 3 } & S. aureus & \multicolumn{1}{c}{ E. coli } \\
\hline $30 \%$ & 0.00 & 0.00 \\
$60 \%$ & 0.00 & 0.00 \\
$90 \%$ & 8.42 & 8.75 \\
\hline
\end{tabular}

Berdasarkan penggolongan kategori kekuatan daya hambat dari Davis Stout (1999) dalam Djajadisastra (2007), maka kekuatan antibakteri ekstrak Spheciospongia sp terhadap bakteri $S$. aureus dan E. coli pada konsentrasi $90 \%$ termasuk pada kategori sedang karena diameter daerah hambatan 5-10 $\mathrm{mm}$ termasuk kategori sedang. Ini membuktikan bahwa pada konsentrasi tinggi ekstrak ini sudah memiliki mekanisme aktivitas antibakteri dalam membunuh atau sudah mampu merusak dinding sel kedua bakteri walaupun kekuatan daya hambatnya masih dikategorikan sedang.

Hasil uji rata-rata ekstrak Agelas sp terhadap bakteri S. aureus menunjukkan diameter zona hambat hanya pada konsentrasi $90 \%$, sedangkan pada konsentrasi 30\% dan 60\% tidak menunjukkan adanya zona hambat di sekitar cakram. Diameter zona hambat konsentrasi $90 \%$ yang ditunjukkan oleh ekstrak spesies ini yaitu $8.83 \mathrm{~mm}$ (Tabel 2). Ini menunjukkan ekstrak Agelas $\mathrm{sp}$ hanya mampu menghambat bakteri $S$. aureus pada konsentrasi tinggi, sedangkan pada konsentrasi rendah ekstrak ini tidak dapat menghambat pertumbuhan bakteri.

Tabel 2. Diameter zona hambat ekstrak Agelas sp terhadap bakteri Staphylococcus aureus dan Escherichia coli

\begin{tabular}{ccc}
\hline \multirow{2}{*}{ Konsentrasi } & \multicolumn{2}{c}{ Diameter Zona Hambat } \\
& \multicolumn{2}{c}{ Ekstrak Agelas sp (mm) } \\
\cline { 2 - 3 } & S. aureus & E. coli \\
\hline $30 \%$ & 0.00 & 7.67 \\
$60 \%$ & 0.00 & 10.17 \\
$90 \%$ & 8.83 & 14.17 \\
\hline
\end{tabular}

Pengujian ekstrak Agelas sp pada bakteri E. coli menunjukkan adanya diameter zona hambat pada setiap konsentrasi. Diameter zona hambat yang terbentuk pada konsentrasi 30\%, 60\% dan 90\% secara berturut-turut yaitu $7.67 \mathrm{~mm}, 10.17 \mathrm{~mm}$ dan $14.17 \mathrm{~mm}$ (Tabel 4). Hal ini menunjukkan ekstrak Agelas sp mempunyai aktivitas antibakteri pada semua konsentrasi, dari setiap konsentrasi terdapat peningkatan zona hambat.

Daya hambat ekstrak Agelas sp pada kedua bakteri terlihat lebih besar pada bakteri E. coli dibandingkan bakteri S. aureus. Hal ini dikarenakan ekstrak spesies ini memiliki senyawa bioaktif yang lebih mampu merusak dinding sel bakteri Gram negatif. Berdasarkan penggolongan kategori kekuatan daya hambat dari Davis Stout (1999) dalam Djajadisastra (2007), maka konsentrasi 90\% ekstrak Agelas sp pada bakteri S. aureus tergolong pada kategori sedang. Konsentrasi 30\% pada bakteri E. coli tergolong pada kategori sedang, sedangkan untuk konsentrasi $60 \%$ dan 90\% tergolong pada kategori kuat. Berdasarkan penggolongan kekuatan daya hambat maka dapat diasumsikan bahwa aktifitas antibakteri yang kuat 
dalam menghambat pertumbuhan bakteri $E$. coli dihasilkan pada konsentrasi ekstrak 60\% dan 90\%.

Hasil uji rata-rata yang diperoleh oleh ekstrak Haliclona sp menunjukkan ekstrak ini mampu menghambat pertumbuhan kedua bakteri. Terlihat jelas bahwa lebar zona hambat yang ditunjukkan ekstrak Haliclona sp memiliki aktivitas yang paling besar diantara dua ekstrak lainnya. Hal ini dikarenakan Haliclona sp memiliki senyawa bioaktif yang dapat menghambat pertumbuhan bakteri $S$. aureus dan E. coli. Rata-rata diameter zona hambat yang ditunjukkan oleh konsentrasi 30\%, 60\% dan 90\% ekstrak Haliclona sp terhadap bakteri $S$. aureus secara berturut-turut yaitu 13.5 mm, 20.67 $\mathrm{mm}$ dan $27.33 \mathrm{~mm}$ (Tabel 3).

Tabel 3. Diameter zona hambat ekstrak Haliclona sp terhadap bakteri Staphylococcus aureus dan Escherichia coli

\begin{tabular}{ccc}
\hline \multirow{2}{*}{ Konsentrasi } & \multicolumn{2}{c}{ Diameter Zona Hambat } \\
& Ekstrak Haliclona sp $(\mathrm{mm})$ \\
\cline { 2 - 3 } & S. aureus & E. coli \\
\hline $30 \%$ & 13.50 & 10.08 \\
$60 \%$ & 20.67 & 12.83 \\
$90 \%$ & 27.3 & 20.83 \\
\hline
\end{tabular}

Hasil yang berbeda yang ditunjukkan oleh ekstrak Haliclona sp terhadap bakteri E. coli, secara berturut-turut rata-rata zona hambat yang terbentuk yaitu $10.08 \mathrm{~mm}$ untuk konsentrasi 30\%, $12.83 \mathrm{~mm}$ untuk konsentrasi $60 \%$ dan $20.83 \mathrm{~mm}$ untuk konsentrasi 90\% (Tabel 3). Terlihat jelas bahwa ekstrak Haliclona sp lebih besar menghambat pertumbuhan bakteri $S$. aureus dibandingkan bakteri E. coli. Hal ini membuktikan bahwa ekstrak Haliclona sp mempunyai senyawa bioaktif yang lebih cocok ke bakteri Gram positif dibandingkan bakteri Gram negatif. Bakteri S. aureus sendiri merupakan Gram positif yang memiliki struktur lapisan dinding sel yang tebal dan berlapis dua yang terdiri atas membran dalam dan peptidoglikan. Bakteri E. Coli merupakan Gram negatif yang memiliki struktur lapisan dinding sel berlapis tiga yang terdiri dari membran luar, peptidoglikan dan membran dalam (Pelczar dan Chan 1988).

Berdasarkan penggolongan kategori kekuatan daya hambat dari Davis Stout (1999) dalam Djajadisastra (2007), maka konsentrasi 30\% ekstrak Haliclona sp terhadap bakteri S. aureus tergolong pada kategori kuat, sedangkan konsentrasi $60 \%$ dan $90 \%$ tergolong pada kategori sangat kuat. Konsentrasi ekstrak 30\%, 60\% dan 90\% terhadap bakteri E. coli mempunyai kekuatan daya hambat tergolong pada kategori kuat. Ini membuktikan aktivitas antibakteri ekstrak Haliclona sp sudah cukup kuat menghambat pertumbuhan bakteri pada konsentrasi 30\%. Suatu zat dikatakan memiliki potensi sebagai antibakteri jika pada konsentrasi yang rendah memiliki daya hambat yang besar (Djajadisastra, 2007). Konsentrasi yang digunakan merupakan salah satu faktor yang mempengaruhi besar kecilnya zona hambat yang terbentuk di sekitar cakram. Semakin lebar diameter zona bening yang terbentuk membuktikan kuatnya senyawa bioaktif itu menghambat pertumbuhan bakteri (Davis Stout, 1999 dalam Djajadisastra, 2007).

\section{Kesimpulan \\ Berdasarkan hasil penelitian dapat} disimpulkan bahwa :

1. Ekstrak Haliclona sp menunjukkan daya hambat dan aktivitas paling baik pada konsentrasi 30\%, $60 \%$ dan $90 \%$ dalam menghambat pertumbuhan bakteri Staphylococcus aureus dan Escherichia coli.

2. Ekstrak Spheciospongia sp hanya menunjukkan daya hambat dan aktivitas antibakteri pada konsentrasi $90 \%$, sedangkan pada konsentrasi $30 \%$ dan $60 \%$ tidak menunjukkan adanya diameter zona hambat di sekitar cakram.

3. Ekstrak Agelas sp menunjukkan daya hambat lebih besar pada bakteri Escherichia coli dibandingkan bakteri Staphylococcus aureus, sehingga potensi antibakteri lebih ke bakteri Gram negatif.

\section{Daftar Pustaka}

Amir, I. dan A. Budiyanto. 1996. Mengenal Spons Laut (Demospongiae) Secara Umum. Oseana. 21 (2) : 15-31.

Asaf, R. 2009. Keterkaitan Kondisi Tutupan Karang Hidup dengan Kandungan Metabolit Sekunder Sponge [Tesis]. Makassar. Pengelolaan Lingkungan Hidup Program Pasca Sarjana Universitas Hasanuddin Makasar.

Astuti, P., G. Alam., S.U.P. Pratiwi., T. Hertiani dan S. Wahyuono. 2003. Skrining Senyawa Antifeksi dari Spons yang Dikoleksi dari Bunaken, Manado. Biota. 08 (2) : 47-52.

Karyawati, A.T. 2010. Aktivitas Antivirus dari Ekstrak Spons Clathria basilana dan Oceanapia amboinensi Terhadap Simian Retrovirus Serotipe-2 Secara In-Vitro [Tesis]. Bogor. Pascasarjana Institut Pertanian Bogor.

Kobayashi, M and R. Rachmaniar. 1999. Overview of Marine Natural Products Chemistry. Prosidings Seminar Bioteknologi Kelautan. LIPI, Jakarta. 2332.

Murniasih, T. 2003. Metabolit Sekunder dari Spons Sebagai Bahan Obat-Obatan. Oseana, XXVIII (3) : 27-33.

Murniasih, T. 2005. Substansi Kimia Untuk Pertahanan Diri dari Hewan Laut Tak Bertulang Belakang. Oseana. XXX (2) : 19-27.

Nursid, M., T. Wikanta., N.D. Fajarningsih dan E. Marraskuranto. 2006. Aktivitas Sitotoksik, Induksi Apoptosis dan Ekspresi Gen p53 Fraksi Metanol Spons Petrosia cf. Nigricans Terhadap 
Sel Tumor Hela. Jurnal Pascapanen dan Bioteknologi Kelautan dan Perikanan, 1 (2).

Pelczar M.J dan E.C.S Chan. 1988. Dasar-dasar Mikrobiologi. Jilid 2. Jakarta. UI Press.

Proksch, P. 1999. Pharmacologically Active Natural Products from Marine Invertebrates and Associated Microorganisms. Prosidings Seminar Bioteknologi Kelautan. LIPI, Jakarta. 33-40.

Rachmaniar, R. 1997. Potensi Spons Asal Kepulauan Spermonde Sebagai Antimikroba. Seminar Perikanan Indonesia II. Ujung Pandang. 2-3.

Rachmaniar, R. 2003. Antikanker Swinholide dari Spons Theonella swinhoei. Jurnal Bahan Alam Indonesia. 2 (04) : 1412-2855.
Rachmaniar, R. 2007. Spons Indonesia Kawasan Timur Keragaman, Distribusi, Kelimpahan, dan Kandungan Metabolit Sekundernya. Oseanologi dan Limnologi di Indonesia. 33 (1): 123-138

Suparno. 2005. Kajian Bioaktif Spons Laut (Porifera Demospongiae) Suatu Peluang Alternatif Pemanfaatan Karang Indonesia dalam Bidang Farmasi. Makalah Pribadi Falsafah Sains (PPs 7002). Bogor. Pasca Sarjana Institut Pertanian Bogor.

Djajadisastra, A.N. 2007. Penapisan Komponen Antibakteri dan Uji Toksisitas dari Spons Perairan Taka Bonerate Sulawesi Selatan [Skripsi]. Bogor. Program Studi Teknologi Hasil Perikanan Fakultas Perikanan dan IImu Kelautan Universitas Institut Pertanian Bogor. 